\title{
Purwarupa Sistem Pembuka Pintu Cerdas Menggunakan Perceptron Berdasarkan Prediksi Kedatangan Pemilik
}

\author{
Brisma Meihar Arsandi*1" ${ }^{1}$ Triyogatama Wahyu Widodo ${ }^{2}$, Faizah $^{3}$ \\ ${ }^{1}$ Program Studi Elektronika Instrumentasi, FMIPA UGM, Yogyakarta \\ ${ }^{2,3}$ Departemen Ilmu Komputer dan Elektronika, FMIPA UGM, Yogyakarta \\ e-mail: *1'brisma.meihar.a@gmail.com, ${ }^{2}$ yogatama@ugm.ac.id, ${ }^{3}$ faizah@ugm.ac.id
}

\begin{abstract}
Sistem prediksi kedatangan merupakan sistem yang memperkirakan waktu kedatangan pemilik rumah pada smarthome. Sistem prediksi digunakan sebagai acuan pada sistem smarthome untuk mempersiapkan perangkat-perangkat elektronik agar saat pemilik rumah sampai, perangkat elektronik tersebut sudah siap digunakan. Sistem prediksi dibuat dengan membagikan jarak dari lokasi pemilik rumah menuju rumah dengan kecepatan berkendara. Prediksi juga menggunakan jaringan syaraf tiruan model perceptron untuk menentukan kondisi perjalanan sedang macet atau lancar dan melakukan koreksi terhadap performa prediksi. Perceptron menggunakan data perjalanan sebelumnya sebagai acuan koreksi performa sistem prediksi. Berdasarkan hasil pengujian pada sistem prediksi, akurasi dari sistem prediksi mencapai $74 \%$ sampai $79 \%$. Akurasi mencapai nilai tersebut karena masih terjadi eror dalam pembacaan lokasi sehingga rute yang diprediksi menjadi tidak sesuai dengan rute yang dilewati. Error terjadi karena akurasi GPS pada ponsel yang kurang bagus yang juga disebabkan penggunaan GPS yang tidak di ruangan terbuka dan GPS pada ponsel hanya terhubung dengan 6 satelit GPS saja. Pada jaringan syaraf tiruan model perceptron dapat membedakan kondisi kemacetan pada perjalanan dengan baik setelah epoch ke 4, dengan nilai bobot 11.09 serta nilai bias 61. Dan pada perceptron dapat mengkoreksi sistem prediksi setelah epoch ke 12 dengan nilai bobot -0.2778 dan 0.2924 serta nilai bias -0.05 .
\end{abstract}

Kata kunci-Smarthome, prediksi, GPS, jaringan syaraf tiruan, perceptron

\begin{abstract}
Arrival prediction system on smarthome is system that cam estimating time of home owner arrival on smarthome. Prediction system used to reference on smarthome system to preparing electronic devices so at home owner arrive, the devices are already to use. Prediction system made by divide distance of home owner location to home by driving velocity. Prediction also use neural network perceptron to determine travel condition are in traffic or not and correcting to predicting perform. Perceptron use last travel data as reference correction to prediction system. Based on testing on prediction system, accuracy of prediction system reach $74 \%$ to $79 \%$. Accuracy reach these values due errors occurred while determining location so predicted route became not match with real condition. Errors occured by GPS usage not on outdoor area and smartphone GPS only detect 6 GPS satellite. Neural network perceptron differ of traffic condition on travel after fourth epoch, with weight value at 11.09 and bias value at 61. And perceptron can correcting prediction system after twelfth epoch with weight values at -0.2778 and 0.2924 also bias value at -0.05 .
\end{abstract}

Keywords - Smarthome, prediction, GPS, neural network, perceptron 


\section{PENDAHULUAN}

$\mathrm{T}$ eknologi smarthome adalah peningkatan kenyamanan dalam hidup [1]. Smarthome adalah sistem aplikasi yang merupakan gabungan antara teknologi dan pelayanan yang dikhususkan pada lingkungan rumah dengan fungsi tertentu yang bertujuan meningkatkan efesiensi, kenyamanan dan keamanan penghuninya [2]. Disamping itu, sistem smarthome memungkinkan pengguna untuk mengelola rumah mereka dari jarak jauh dan menyediakan sistem keamanan untuk pengguna. Penggunaan sistem smarthome dilakukan dengan melakukan otomasi pada berbagai perangkat di rumah sehingga sistem dapat mengerjakan tugas yang dilakukan manusia atau yang tidak mungkin dilakukan oleh manusia. Dengan kata lain, untuk menyederhanakan dan mempermudah pekerjaan manusia [3]. Dengan adanya otomasi, sistem dapat mengerjakan tugas-tugas yang dilakukan pemilik rumah ketika ada di rumah, saat pergi, atau bahkan ketika sedang kembali menuju rumah. Perangkat sensor dan aktuator yang terhubung menyediakan kemampuan untuk berbagi informasi antara platform melalui sebuah sistem memungkinkan pengembangan aplikasi dicapai dengan pengambilan data yang bagus, analisa data dan informasi dengan cloud computing sebagai pemersatu jaringan [4]. Apabila sistem sudah siap sebelum pemilik rumah sampai, maka daya listrik yang digunakan menjadi boros. Namun, apabila sistem belum siap ketika pemilik rumah sampai, maka pemilik rumah harus menunggu agar sistem siap digunakan. Oleh karena itu, sistem smarthome memerlukan sistem prediksi kedatangan pemilik rumah.

Pada sistem prediksi, terdapat faktor yang menentukan prediksi tersebut. Faktor yang menentukan prediksi pada perjalanan diantaranya adalah kondisi perjalanan, struktur jalanan, dan cuaca[5]. Perubahan kondisi pada faktor prediksi dapat berubah secara tiba-tiba. Oleh karena itu, diperlukan sistem yang dapat belajar dan beradaptasi dengan waktu tersebut. Sejauh ini, terdapat banyak metode yang diterapkan pada sistem untuk melakukan adaptasi terhadap hal-hal baru dan mempelajarinya, salah satunya adalah jaringan syaraf tiruan. Jaringan syaraf adalah sebuah program komputer yang beroperasi dengan cara yang analog dengan jaringan syaraf alami di otak[6]. Jaringan syaraf tiruan mempunyai banyak kelebihan dibandingkan sistem konvensional. Jaringan syaraf tiruan mewakili pikiran manusia untuk mendekatkan diri dengan komputer, maksudnya jaringan syaraf tiruan dirancang agar komputer dapat bekerja seperti otak manusia [7]. Jaringan syaraf tiruan model perceptron memiliki keunggulan diantaranya; modelnya yang sederhana, efisien, dapat memisahkan nilai linear, dan mudah dianalisa[8].

\section{METODE PENELITIAN}

Dalam kehidupan sehari-hari, manusia memiliki aktivitas yang dilakukan setiap hari seperti makan, tidur, atau bekerja. Aktivitas tersebut dapat dilakukan di rumah maupun luar rumah. Aktivitas manusia diluar rumah terkadang dilakukan di dekat rumah maupun jauh dari rumah. Ketika aktivitas dilakukan jauh dari rumah, diperlukan waktu untuk perjalanan menuju tempat tersebut dan juga sebaliknya.

Pada sistem prediksi kedatangan, terdapat beberapa faktor yang menentukan prediksi waktu antara lain; kondisi perjalanan, struktur jalan yang dilewati, dan cuaca. Perubahan nilai pada faktor tersebut dapat terjadi secara tiba-tiba. Sistem prediksi memerlukan metode agar yang dapat melakukan adaptasi terhadap hal-hal baru dan mempelajarinya, yaitu menggunakan metode jaringan syaraf tiruan. Dari berbagai jenis jaringan syaraf tiruan, perceptron memiliki keunggulan diantaranya; modelnya yang sederhana, efisien, dapat memisahkan nilai linear, dan mudah dianalisa. Dengan adanya jaringan syaraf tiruan perceptron, diharapkan dapat mengatasi perubahan kondisi pada faktor yang menentukan nilai prediksi pada sistem prediksi kedatangan.

Sistem yang dirancang dalam penelitian ini meliputi sistem prediksi kedatangan pemilik rumah, rancangan perceptron dan penguncian pintu depan. Rancangan sistem prediksi kedatangan pemilik rumah diawali dengan pengiriman data koordinat yang

IJEIS Vol. 7, No. 1, April 2017 : 83 - 92 
digambarkan seperti Gambar 1. GPS pada smartphone diaktifkan oleh pemilik rumah dan kemudian smartphone mengirimkan data koordinat ke Ubidots.

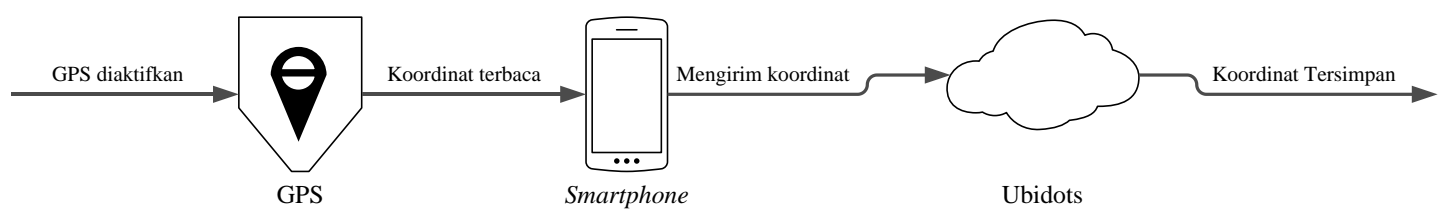

Gambar 1 Pengiriman data koordinat

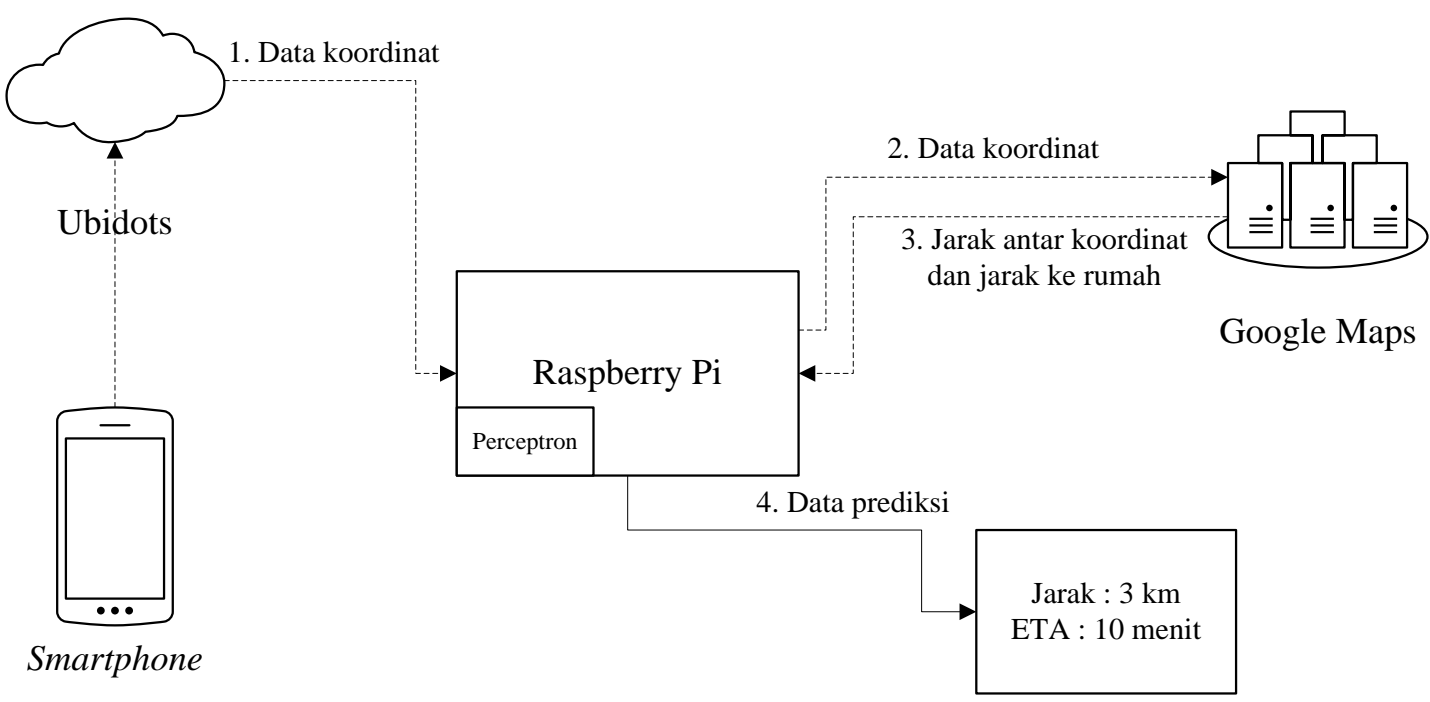

Gambar 2 Sistem prediksi kedatangan pemilik rumah

Setelah data disimpan di Ubidots, proses dilanjutkan dengan sistem prediksi kedatangan pemilik rumah seperti Gambar 2. Data koordinat diambil oleh sistem dari database Ubidots oleh Raspberry Pi. Raspberry Pi kemudian menghitung jarak perjalanan pemilik rumah menuju rumah dan juga menghitung jarak perpindahan antar koordinat menggunakan layanan Google Maps. Setelah didapat jarak perpindahan antar koordinat, Raspberry Pi kemudian menghitung kecepatan berkendara pemilik rumah. Data kecepatan berkendara dan jarak dari rumah kemudian dianalisa menggunakan perceptron di Raspberry Pi. Hasil analisa perceptron kemudian diolah dan menghasilkan prediksi kedatangan pemilik rumah. Apabila kondisi perjalanan macet, maka kecepatan yang digunakan sebagai referensi pada sistem adalah kecepatan sebelum kemacetan terjadi.

Pada sistem prediksi, perceptron digunakan sebanyak dua kali. Penggunaan pertama yaitu untuk membedakan kondisi jalan sedang lancar atau macet, sedangkan yang kedua yaitu untuk membandingkan nilai prediksi yang sedang berlangsung dengan waktu aktual pada perjalanan sebelumnya.

Pada program perceptron, program dilatih dahulu dengan data training sehingga didapat nilai bias dan bobot yang efektif. Data training didapat dengan melakukan perjalanan dan didapat nilai kecepatan saat berkendara serta nilai target ditentukan berdasarkan kecepatan berkendara saat macet dan lancar. Dari perjalanan tersebut didapat 1500 data berupa koordinat dan interval waktu yang dijadikan data training. Pelatihan dilakukan dengan mengalikan nilai masukan dengan nilai bobot pada semua masukan dan dijumlahkan serta ditambahkan dengan nilai bias yang disebut respon unit keluaran. Apabila hasil belum sesuai dengan target, maka

Purwarupa Sistem Pembuka Pintu Cerdas Menggunakan Perceptron...(Brisma Meihar Arsandi) 
nilai bobot dan nilai bias ditambahkan atau dikurangi hingga hasilnya sesuai target. Pelatihan dilakukan dengan alur seperti pada Gambar 3. Sedangkan pada persamaan (1) menunjukkan cara melakukan klasifikasi nilai pelatihan berdasarkan threshold $\theta$ dan pada persamaan (2) dan (3) menunjukkan cara mendapatkan nilai threshold. Berdasarkan hasil pelatihan menggunakan data training, didapat nilai batas kemacetan yaitu $5.5 \mathrm{~m} / \mathrm{s}$ pada nilai bobot 11.099 dan bias bernilai 61. Untuk mendapat nilai tersebut, dibutuhkan lima kali terasi yang perubahan nilainya ditunjukkan pada Tabel 1 dan setelah lima kali epoch, nilai bobot dan bias tidak berubah lagi. Para program perceptron, input masukan berupa data kecepatan. Jika nilai masukkan kecepatan dibawah 5.5, perceptron menghasilkan nilai 0. Sedangkan jika nilai masukkan kecepatan bernilai 5.5 atau lebih besar, maka perceptron menghasilkan nilai 1 .

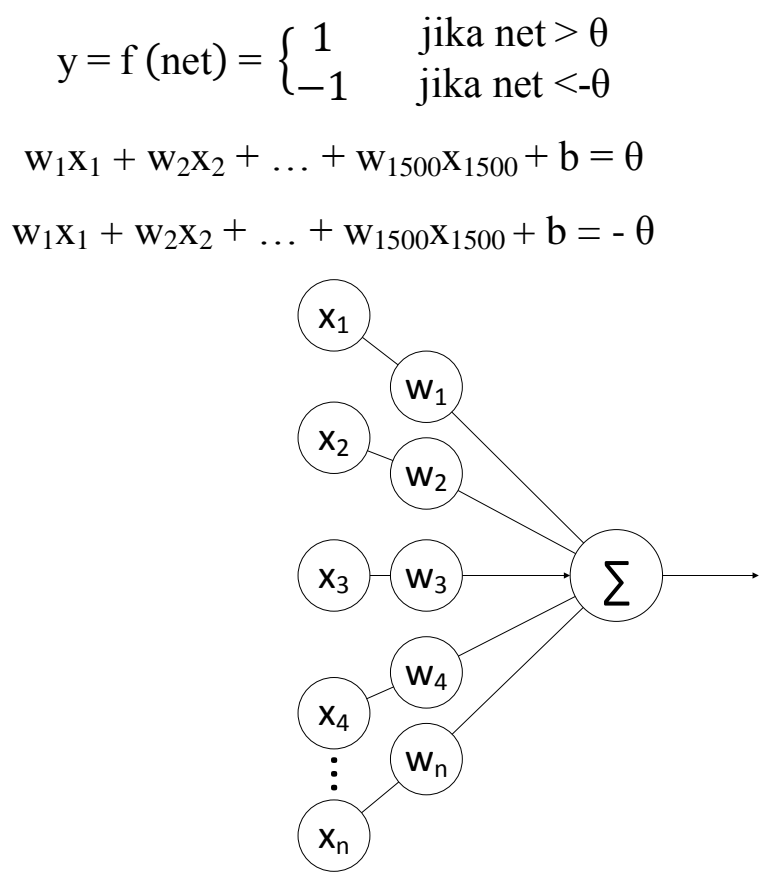

Gambar 3 Diagram pelatihan perceptron

Tabel 1 Nilai bobot dan bias setiap epoch.

\begin{tabular}{|c|c|c|}
\hline Epoch & Bobot & Bias \\
\hline 0 & 6.989811 & 39 \\
\hline 1 & 10.28932 & 46 \\
\hline 2 & 11.95601 & 55 \\
\hline 3 & 10.44026 & 57 \\
\hline 4 & 11.09946 & 61 \\
\hline 5 & 11.09946 & 61 \\
\hline
\end{tabular}

Rancangan sistem pembuka pintu merupakan fitur yang diujikan pada sistem prediksi. Jika prediksi kurang dari 10 detik untuk sampai, maka kunci pintu terbuka. Pintu kemudian mengunci otomatis setelah 10 menit terbuka. Dan prediksi lebih dari 10 detik dari perkiraan sampai rumah, maka kunci pintu tidak terbuka seperti diagram pada Gambar 4. 


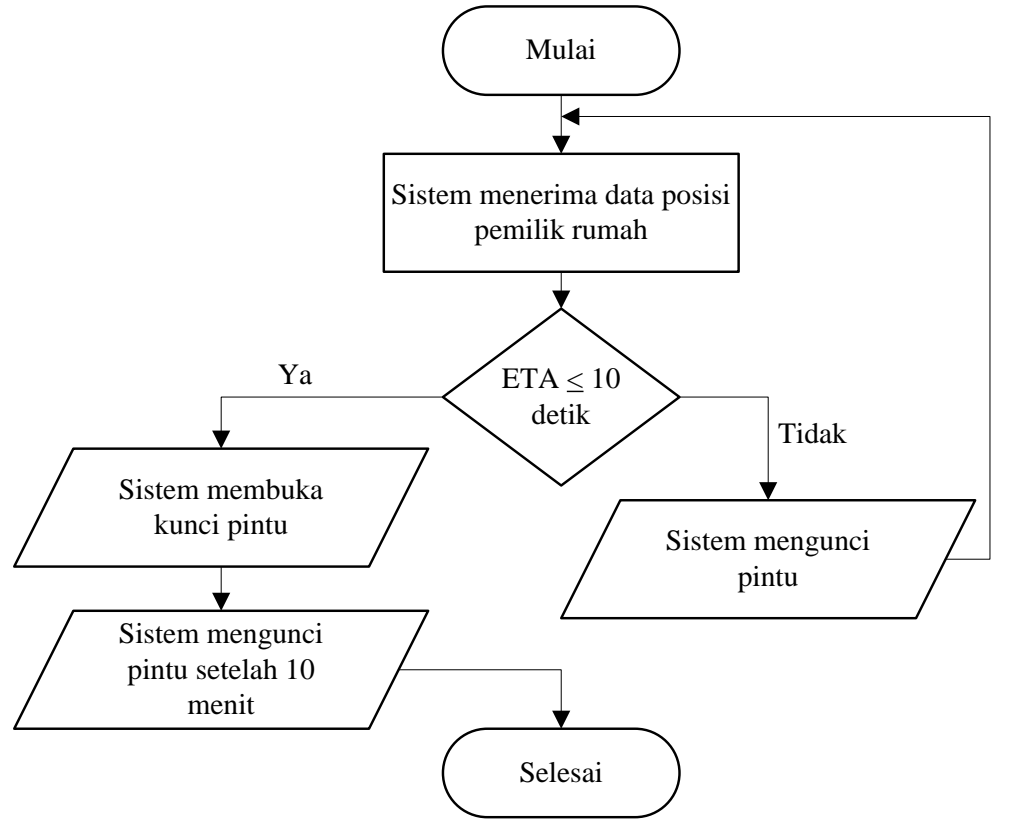

Gambar 4 Mekanisme menutup pintu menggunakan hasil prediksi

Sistem ini diimplementasikan dengan menggunakan Raspberry Pi untuk mengolah sistem prediksi dan perceptron seperti pada Gambar 5. Sedangkan pada mekanisme membuka pintu menggunakan solenoid doorlock dan modul relay.

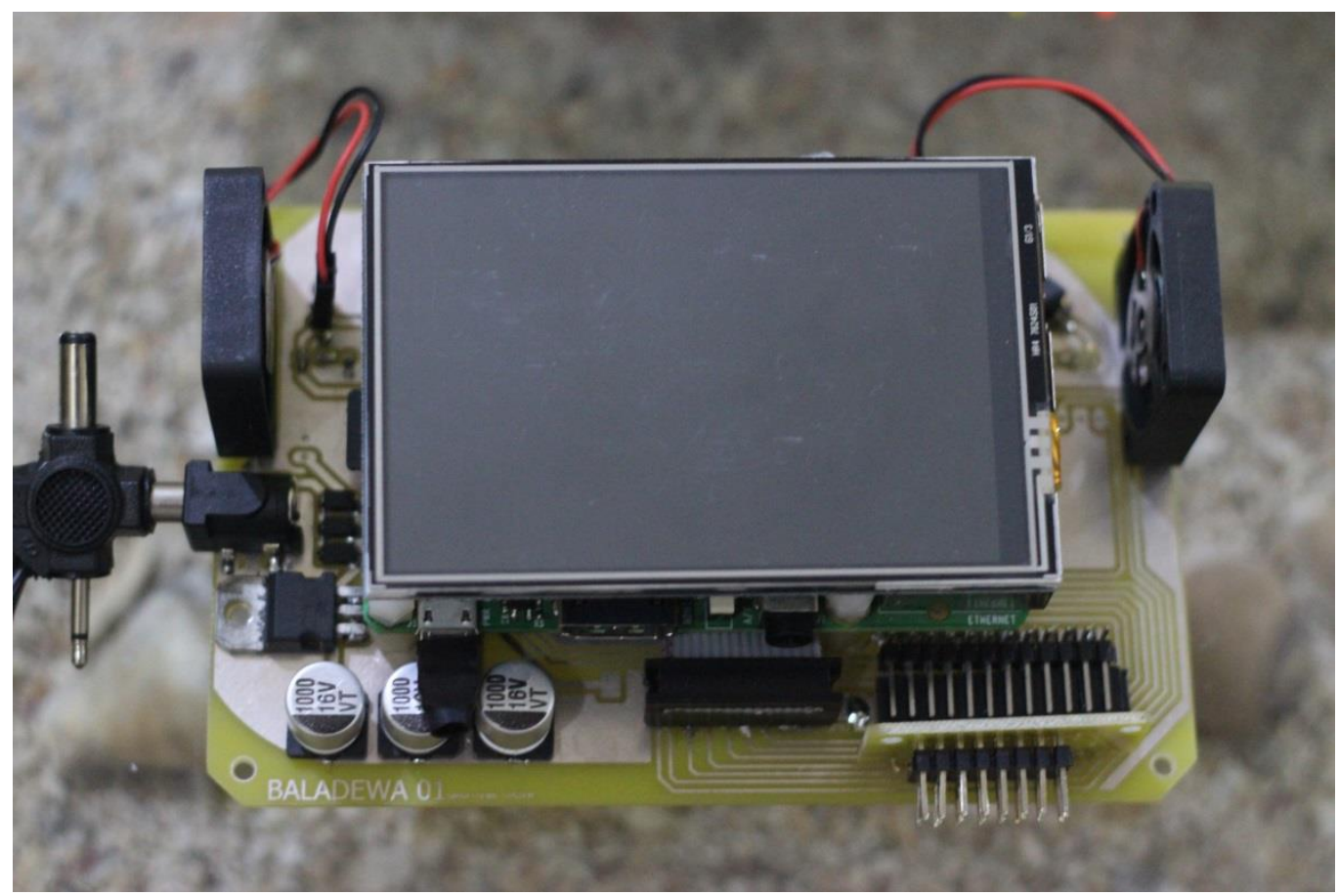

Gambar 5 Rangkaian sistem

\section{HASIL DAN PEMBAHASAN}

Prediksi waktu pada sistem prediksi adalah bagian dari sistem yang memperkirakan waktu kedatangan pemilik rumah. Prediksi waktu ditentukan nilainya berdasarkan hasil operasi 
bagi antara jarak pemilik rumah menuju rumah dengan kecepatan perjalanan. Pada program prediksi waktu kedatangan, hasil dari perceptron juga dimasukkan ke dalam program. Jika hasil perceptron menyatakan macet, kecepatan yang digunakan adalah kecepatan sebelum terjadi kemacetan.

Program prediksi juga menggunakan perceptron untuk meningkatkan akurasi dari prediksi itu sendiri. Perceptron digunakan untuk membandingkan dengan data perjalanan sebelumnya dengan data prediksi yang berlangsung. Data perjalanan sebelumnya yang digunakan adalah selisih waktu aktual pada perjalanan sebelumnya yang jaraknya terhadap rumah mendekati dengan jarak terhadap rumah pada prediksi yang berlangsung. Apabila nilai prediksi lebih besar, maka nilai prediksi dikurangi 30. Apabila nilai prediksi lebih kecil, maka nilai prediksi ditambah 30 . Nilai 30 yang berarti 30 detik diberikan sebagai nilai koreksi untuk prediksi.

Sebelum melakukan pengujian sistem secara keseluruhan, sistem diuji dahulu koneksi antara perangkatnya; dalam hal ini adalah GPS pada ponsel hingga Raspberry Pi. GPS pada ponsel diuji performanya dengan mengirim data menuju Ubidots dan diambil oleh Raspberry Pi dalam waktu 30 menit sambil melakukan perjalanan. Kemudian dilihat data yang diterimanya. Pada pengujian ini, GPS pada ponsel diatur untuk mengirimkan koordinat dengan interval satu detik, tetapi waktu penerimaan koordinat oleh Raspberry Pi tidak sesuai dengan pengaturan pada ponsel. Hasil pengiriman koordinat dapat dilihat pada Tabel 2. Penerimaan data koordinat terjadi dalam satu menit atau lebih.

Table 2 Data GPS yang diterima oleh Raspberry Pi

\begin{tabular}{|l|c|c|c|c|}
\hline No. & Tanggal & Jam & Lattitude & Longitude \\
\hline 1 & $8 / 9 / 2016$ & $17: 52.3$ & -7.74183 & 110.3986 \\
\hline 2 & $8 / 9 / 2016$ & $17: 51.2$ & -7.74183 & 110.3986 \\
\hline 3 & $8 / 9 / 2016$ & $17: 36.5$ & -7.74176 & 110.3986 \\
\hline 4 & $8 / 9 / 2016$ & $17: 35.5$ & -7.74176 & 110.3986 \\
\hline 5 & $8 / 9 / 2016$ & $17: 33.7$ & -7.74176 & 110.3986 \\
\hline 6 & $8 / 9 / 2016$ & $17: 32.6$ & -7.74176 & 110.3986 \\
\hline 7 & $8 / 9 / 2016$ & $17: 31.5$ & -7.74176 & 110.3986 \\
\hline 8 & $8 / 9 / 2016$ & $17: 30.5$ & -7.74176 & 110.3986 \\
\hline 9 & $8 / 9 / 2016$ & $17: 29.5$ & -7.74176 & 110.3986 \\
\hline 10 & $8 / 9 / 2016$ & $17: 28.4$ & -7.74176 & 110.3986 \\
\hline 11 & $8 / 9 / 2016$ & $17: 27.3$ & -7.74176 & 110.3986 \\
\hline 12 & $8 / 9 / 2016$ & $17: 26.2$ & -7.74176 & 110.3986 \\
\hline 13 & $8 / 9 / 2016$ & $17: 25.0$ & -7.74176 & 110.3986 \\
\hline 14 & $8 / 9 / 2016$ & $17: 23.8$ & -7.74176 & 110.3986 \\
\hline 15 & $8 / 9 / 2016$ & $17: 22.8$ & -7.74176 & 110.3986 \\
\hline
\end{tabular}

Pada pengujian sistem, dilakukan perjalanan dari gedung MIPA Utara Universitas Gadjah Mada menuju Jalan Kinanti kelurahan Condongcatur yang kedua tempat tersebut berada di Sleman, Yogyakarta. Pengujian dilakukan sebanyak dua kali dengan rute yang sama. Gambar 6 dan Gambar 7 menunjukkan peta rute perjalanan, sedangkan garis biru menunjukkan rute yang terbaca oleh GoogleMaps berdasarkan koordinat GPS yang terbaca. Pada garis biru di Gambar 6 dan Gambar 7, terdapat jalur rute yang memutar. Hal ini disebabkan akurasi GPS yang tidak selalu bagus sehingga mengakibatkan pergeseran koordinat terbaca yang membuat GoogleMaps merekomendasikan jalan memutar untuk mencapai lokasi tersebut serta

IJEIS Vol. 7, No. 1, April 2017 : 83 - 92 
menghitung antar koordinat tersebut dengan rute memutar. Akurasi GPS tidak selalu bagus dikarenakan lokasi GPS yang tidak selalu berada di tempat terbuka[9]. Dan untuk akurasi yang optimal, GPS setidaknya terhubung dengan 8-12 satelit GPS [10]. Sedangkan pada GPS ponsel, hanya di dapat 6 satelit GPS saja.

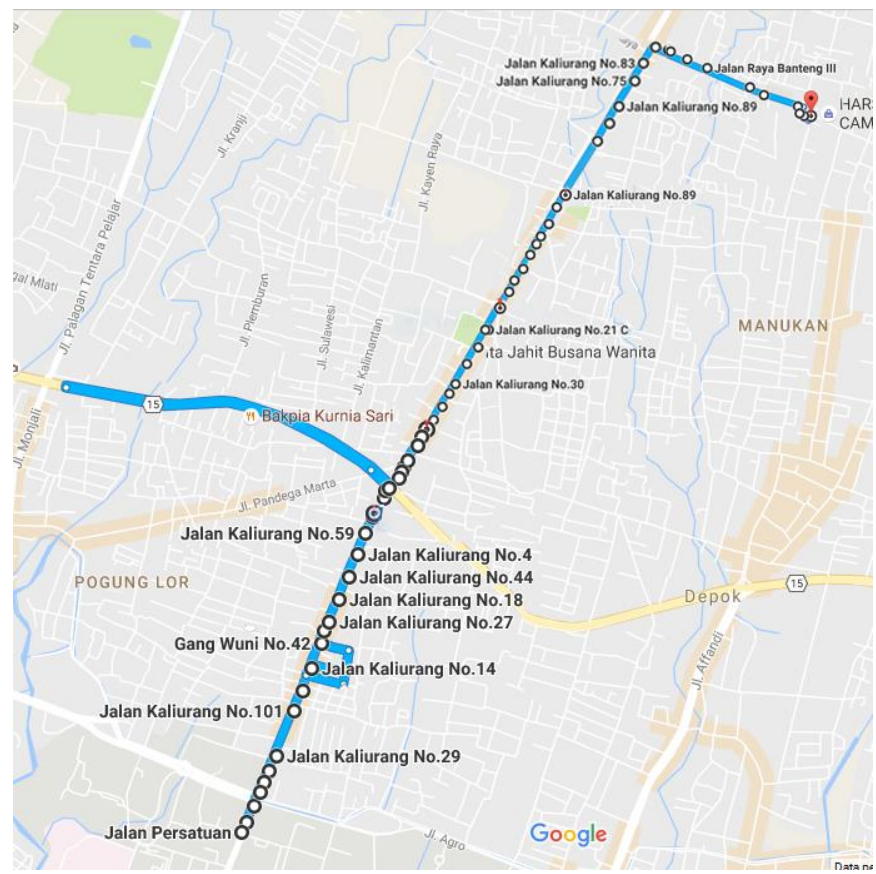

Gambar 6 Rute pengujian pada hari pertama

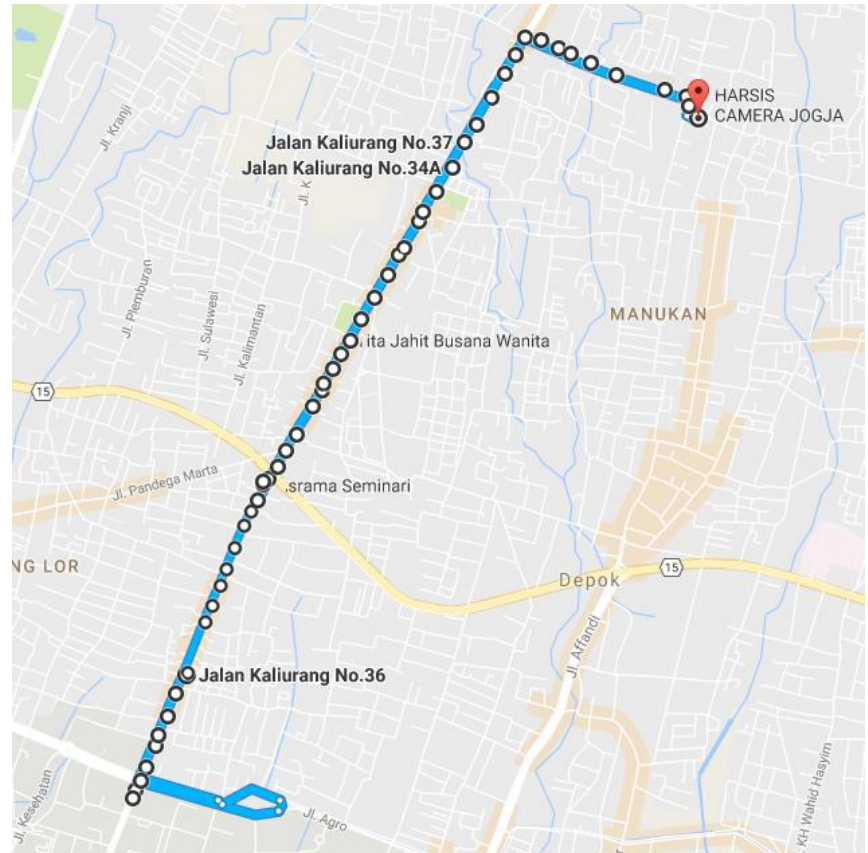

Gambar 7 Rute pengujian pada hari kedua

Berdasarkan pengujian yang dilakukan, kemudian didapat waktu prediksi serta waktu aktual. Waktu prediksi adalah hasil prediksi yang didapatkan dari perhitungan sistem berdasarkan lokasi, jarak dan kecepatan pemilik rumah terhadap rumah. Sedangkan waktu 
aktual adalah waktu yang didapat setelah perjalanan selesai, waktu aktual merupakan waktu yang dibutuhkan pemilik rumah menuju rumah dari lokasi yang terbaca oleh GPS.

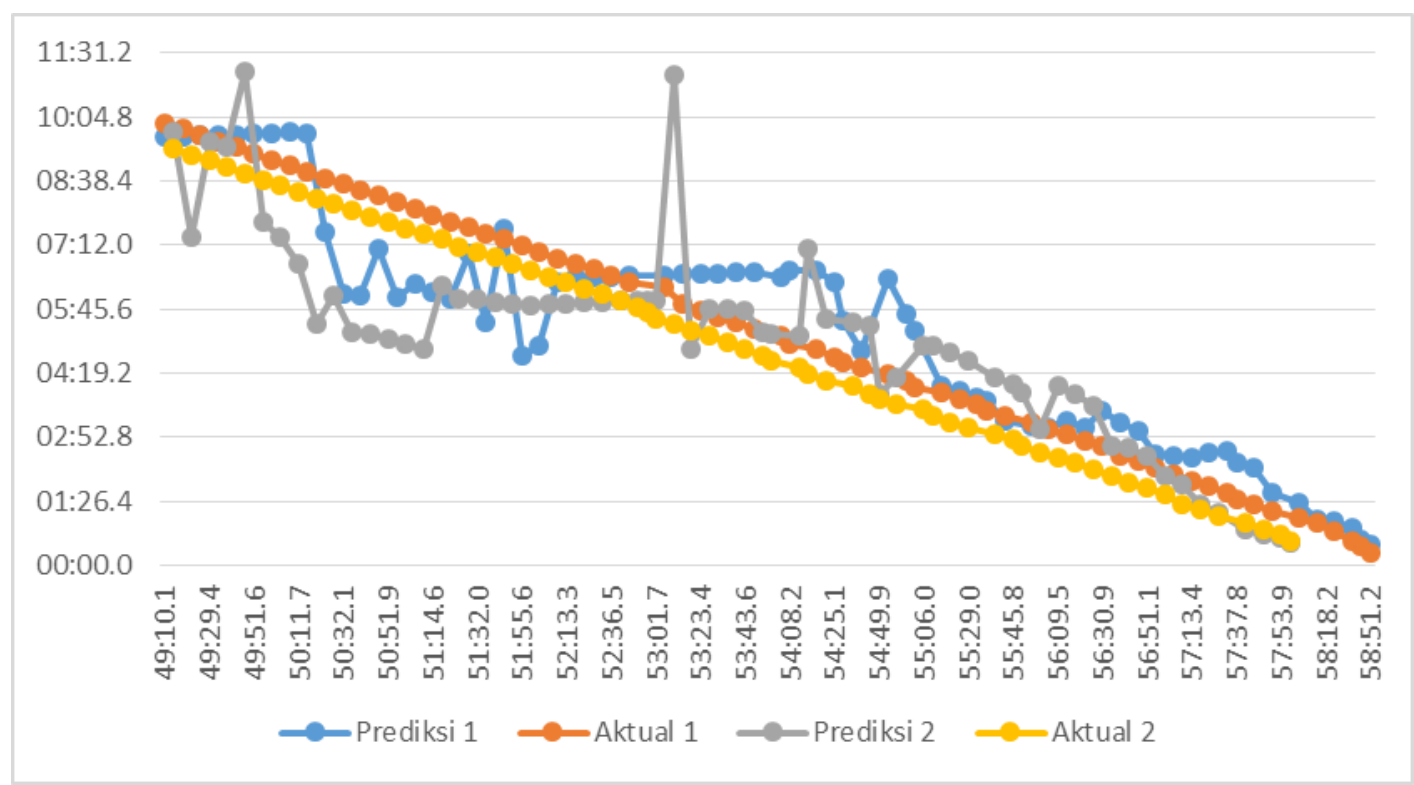

Gambar 8 Grafik perbandingan waktu aktual dan waktu prediksi

Pada grafik di Gambar 8, waktu aktual pada hari pertama dan hari kedua memiliki perbedaan. Dari perbandingan prediksi dengan waktu aktual, kemudian didapat nilai akurasi.

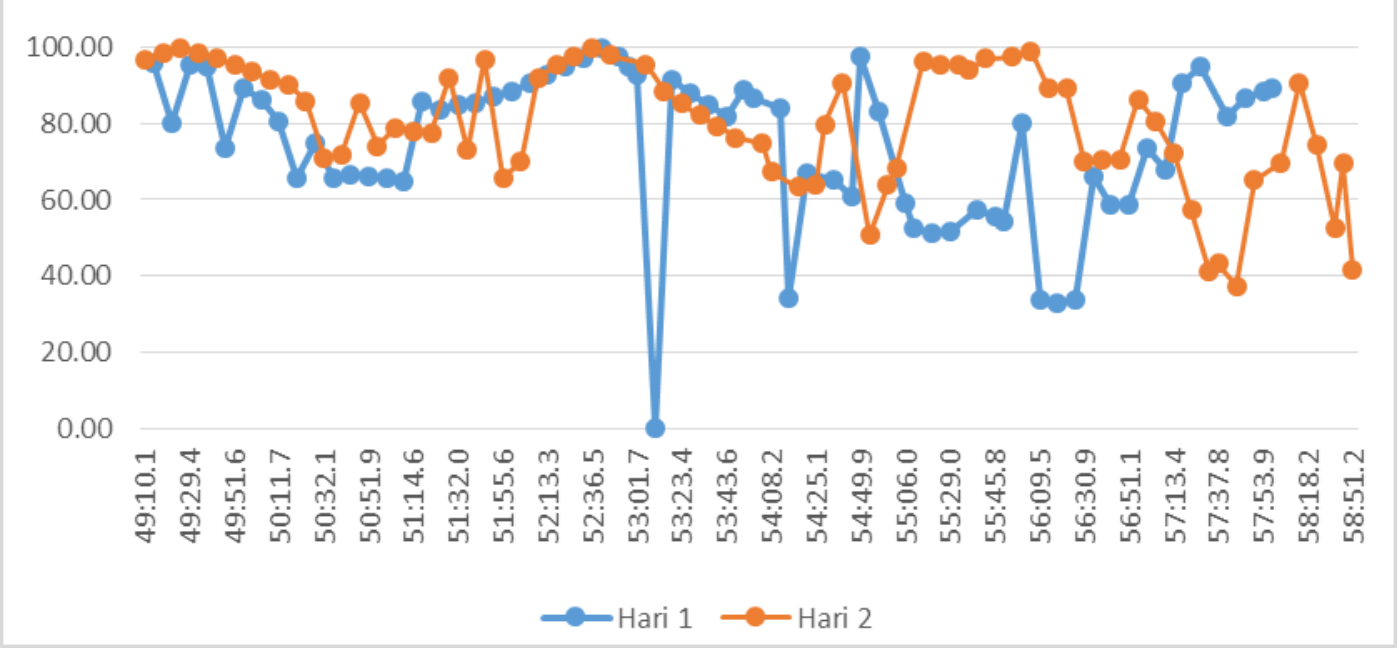

Gambar 9 Grafik perbandingan akurasi hasil pengujian

Berdasarkan grafik pada Gambar 9, didapat rata-rata akurasi akurasi pada hari pertama sebesar $74 \%$ dan pada hari kedua sebesar $79 \%$. Akurasi pada pengujian dalam satu perjalanan dapat berkurang dikarenakan adanya selisih yang besar antara waktu aktual dan prediksi.

Pada perceptron pertama digunakan untuk menentukan kemacetan; program dibuat untuk membedakan kemacetan dengan masukan berupa angka. Perceptron menyatakan -1 apabila nilai kecepatan di bawah 5.5 dan perceptron menyatakan 1 apabila nilai kecepatan lebih dari sama dengan 5.5. Pengaturan untuk nilai efektif perceptron pertama adalah bobot awal bernilai 0 , bias awal bernilai 0 , serta learning rate yang bernilai 1 . Hasil terbaik perceptron pertama dicapai setelah epoch ke 4 dengan nilai bobot 11.09 serta nilai bias 61 .

Pada perceptron kedua, program digunakan untuk mengubah nilai prediksi dengan acuan data aktual pada perjalanan sebelumnya. Perceptron memiliki dua masukan yaitu data 
prediksi yang sedang berlangsung dan data perjalanan sebelumnya dengan posisi jarak yang mendekati dengan perjalanan yang sedang berlangsung, dan perceptron berfungsi untuk membandingkan kedua tersebut. Perceptron menyatakan 1 apabila nilai masukan pertama sama atau kurang dari masukan kedua, perceptron menyatakan -1 apabila nilai masukan lebih besar dari masukan kedua. Pengaturan untuk nilai efektif perceptron kedua adalah bobot awal bernilai 0 , bias awal bernilai 0 , serta learning rate yang bernilai 0.01 . Hasil terbaik perceptron kedua dicapai setelah epoch ke 12 dengan nilai bobot -0.2778 dan 0.2924 serta nilai bias -0.05 .

\section{KESIMPULAN}

Berdasarkan hasil pengamatan, pengujian, dan analisis pada hasil yang diperoleh, kesimpulan yang dapat diambil adalah sebagai berikut;

1. Telah diimplementasikan sistem prediksi kedatangan pemilik rumah yang menggunakan sistem jaringan syaraf model perceptron pada smarthome.

2. Akurasi dari sistem prediksi sebesar $74 \%$ - $79 \%$ dan akurasi pada perceptron sebesar $100 \%$.

3. Pengaturan untuk nilai efektif perceptron pada penentu kondisi perjalanan adalah bobot awal bernilai 0 , bias awal bernilai 0 , serta learning rate yang bernilai 1 .

4. Hasil terbaik perceptron pada penentu kondisi perjalanan dicapai setelah epoch ke 4 dengan nilai bobot 11.09 serta nilai bias 61 .

5. Pengaturan untuk nilai efektif perceptron pada sistem prediksi adalah bobot awal bernilai 0 , bias awal bernilai 0 , serta learning rate yang bernilai 0.01 .

6. Hasil terbaik perceptron pada penentu kondisi perjalanan dicapai setelah epoch ke 12 dengan nilai bobot -0.2778 dan 0.2924 serta nilai bias -0.05 .

\section{DAFTAR PUSTAKA}

[1] Teoh, \& Tan. (2010). A neural network approach towards reinforcing smart home security. Information and Telecommunication Technologies (APSITT), 2010 8th Asia-Pacific Symposium on.

[2] S, T. F. Y., \& Azman, N. (2009). Perancangan Software Aplikasi Pervasive Smart Home, 2009(Snati), 1-5.

[3] Dey, C., \& Choudhary, R. (2016). Making Smart Home Truly Smart, 6(8), 322-326.

[4] Jayavardhana Gubbi, Rajkumar Buyya, Slaven Marusic, M. P. (2013). Internet of Things (IoT): A vision, architectural elements, and future directions. Melbourne: The University of Melbourne.

[5] Sun, D., Luo, H., Fu, L., Liu, W., Liao, X., \& Zhao, M. (2007). Predicting Bus Arrival Time on the Basis of Global Positioning System Data. Transportation Research Record Journal of the Transportation Research Board Transportation Research Board of the National Academies, (2034), 62-72. http://doi.org/10.3141/2034-08.

[6] Zwass, V. (2014). Neural Network

[7] Yani, E. (2005). Pengantar Jaringan Syaraf Tiruan. Retrieved from https://trirezqiariantoro.files.wordpress.com/2007/05/jaringan_syaraf_tiruan.pdf

[8] Watts, M. J. (2004). Perceptrons. Retrieved from mike.watts.net.nz/Teaching/IIS/Lecture9.pdf. 
[9] Hwang, Y., An, J., \& Lee, J. (2016). The Standard for the Selection of the Appropriate GPS in the Outdoor Environment \& the Analysis of the Performance for the Improvement of Reception.

[10] Sathyamorthy, D., Shafii, S., Amin, Z. F. M., Jusoh, A., \& Ali, S. Z. (2015). Evaluating the Trade-Off between Global Positioning System (GPS) Accuracy and Power Saving from Reduction of Number of GPS Receiver Channels, 221-224. 